\title{
Ameliorative effect of selenium yeast on blood glucose level in streptozotocin induced diabetes in wistar rats
}

\author{
Mohammed Kabir Ahmed ${ }^{1, ~ *, ~ M o h a m m e d ~ A l i y u ~}{ }^{1}$, Tanko Yusuf ${ }^{1}$, Musa Kabir Yusuf ${ }^{2}$ \\ ${ }^{1}$ Department of Human Physiology, Ahmadu Bello University, Zaria, Kaduna State, Nigeria \\ ${ }^{2}$ Department of Phamacognosy and Drug Design, Ahmadu Bello University, Zaria, Kaduna State, Nigeria
}

Email address:

mka4u2002@yahoo.com (M. K. Ahmed)

\section{To cite this article:}

Mohammed Kabir Ahmed, Mohammed Aliyu, Tanko Yusuf, Musa Kabir Yusuf. Ameliorative Effect of Selenium Yeast on Blood Glucose Level in Streptozotocin Induced Diabetes in Wistar Rats. Cell Biology. Vol. 3, No. 1, 2015, pp. 14-18. doi: 10.11648/j.cb.20150301.12

\begin{abstract}
The study investigated the effect of selenium-yeast on Blood glucose level in streptozotocin induced diabetic wistar rats. Diabetes mellitus was induced by single intraperitoneal (i.p) injection of streptozotocin dissolved in $0.1 \mathrm{ml}$ fresh cold citrate buffer $\mathrm{pH} 4.5$ at a dose of $60 \mathrm{mg} / \mathrm{kg}$ body weight, after which the rats were randomly divided into seven groups. Group 1 Diabetic treated with $0.1 \mathrm{mg} / \mathrm{kg}$ of selenium-yeast. Group 2 Diabetic treated with $0.2 \mathrm{mg} / \mathrm{kg}$ of selenium-yeast respectively. Group 3 Diabetic treated with $1 \mathrm{mg} / \mathrm{kg}$ of Glibenclamide (GB). Group 4 served as normoglycemic control group and was administered normal saline $(5 \mathrm{ml} / \mathrm{kg}$ ), Group 5 Diabetic untreated group received normal saline $(5 \mathrm{ml} / \mathrm{kg})$, Group 6 Diabetic treated with $300 \mathrm{mg} / \mathrm{kg}$ moderate dose of Aspirin. Group 7 Diabetic treated with $120 \mathrm{mg} / \mathrm{kg}$ of Ibuprofen. All treatments were given orally for two weeks. The results of the present study showed that blood plasma glucose level in the diabetic control group was significantly higher when compared with the normal control group in the entire 4-weeks of the study. Blood plasma glucose levels were significantly lower $(\mathrm{p}<0.05)$ in the Group treated with $0.2 \mathrm{mg} / \mathrm{kg}$ selenium-yeast and the standard drug Glibenclamide at WK1 and WK3 when compared with the diabetic control Group. In conclusion. The above results suggest that Selenium-yeast has shown to possess hypoglycaemic property that is comparable to the oralhypoglycaemic drug, glibenclamide.
\end{abstract}

Keywords: Selenium-Yeast, Streptozotocin, Glibenclamide, Aspirin, Ibuprofen

\section{Introduction}

Diabetes is a common metabolic disorder characterized by hyperglycemia due to an absolute or relative insulin deficiency $[22,1]$. It affects essential biochemical pathways of the body including carbohydrate, protein, and lipid metabolisms. The World Health Organization (WHO), estimated that there were 171 million people in the world with diabetes in the year 2008 and this is projected to increase by over a $100 \%$ to 366 million by 2030 [1]. Diabetes is associated with reduced life expectancy, significant high mortality and diminished quality of life. In 2005 an estimated 1.1 million people died from diabetes and diabetic related complications [2]. Its prevalence is rising globally, including the rural Nigerian populations [3].

The challenges and thus, the solutions in the provision of healthcare that would improve outcome for diabetes in low and middle income countries are many and can be found at multiple levels. Patient-related factors are of extreme importance, these ranges from low levels of self-management practices, lack of adherence to lifestyle changes and medication and lack of faith in the conventional management procedures. Many African populations still regard alternative healing systems as the primary source of healthcare or alternatively, consult both traditional or folk healers that usually promote the concept that diabetes is curable and have been found to be also reluctant to refer clients to medical practitioners $[4,5]$. This, however, is undermined by two key factors; the high cost of drugs and recommended foods as well as the psychosocial burden imposed by the daily oral hypoglycaemic drugs and therapeutic routines. Moreover, spiritual causal theories of diabetes such as sorcery and witchcraft are still found in many African populations, particularly in rural communities [6].

However, little is known about the beneficial effect of Selenium (Se), a trace element with both antioxidant and 
anti-inflammatory properties that offers several health benefits to animals and humans $[7,8,9]$.

Selenium is found in minute amounts in foods, with the richest sources being from meats, fish, whole grains, and dairy products. The selenium content of vegetables is dependent on the soil in which they are grown [7,9].

In recent years, selenium (Se) research has attracted tremendous interest because of its important role in antioxidant seleno-enzymes, such as glutathione peroxidase (GPx) and thioredoxinreductase, which protect against oxidative stress [8].The organic form of selenium provided by selenium-yeast has been shown to differ in bioavailability and metabolism compared with inorganic (e.g., selenate, selenite) forms of dietary selenium [10]. Furthermore, selenium-yeast has been used in a wide range of studies aimed at examining the importance of selenium status in the incidence and progression of a variety of infectious and degenerative diseases [11].

\section{Materials and Methods}

\subsection{Experimental Animals}

Thirty five (35) adult male Wistar rats weighing (180 200) grams were used for the study. The animals were housed in polypropylene cages under standard laboratory conditions and had free access to food and water ad-libitum. Animals were allowed to acclimatize to the laboratory environment over a period of 14 days before the commencement of the experiments. Animal care and use were conducted in accordance with the Guide for the Care and Use of Laboratory Animals, Institute for Laboratory Animal Research, National Institute of Health (NIH Publications No. 80-23; 1996)

\subsection{Drugs and Reagents}

All drugs and reagents were obtained commercially and were of analytical grades. The drugs and reagents obtained include Streptozotocin (Sigma Aldrich), Selenium-yeast (Sigma-Aldrich), Digital glucometer (Accu-check advantage, Roche Diagnostic, Company), Weighing balance (GF 2000), dissecting set, syringes and needles (Sologuard Medical Device P.V.T Ltd., Chema-600 096, India, ML No. 750).

\subsection{Induction of Experimental Diabetes Mellitus}

Diabetes mellitus was induced by single intraperitoneal injection of $60 \mathrm{mg} / \mathrm{kg}$ body weight dose of streptozotocin dissolved in $0.1 \mathrm{ml}$ fresh cold citrate buffer $\mathrm{pH} 4.5$ into $16 \mathrm{~h}$ fasted rats. Three days after streptozotocin injection $(72 \mathrm{~h})$, blood samples were taken from tail artery of the rats [25] for determination of blood glucose levels using the glucoseoxidase principle. Rats with blood glucose levels greater than $200 \mathrm{mg} / \mathrm{dl}$ were considered diabetic and were used for the study. Thirty (30) rats showed streptozotocin-induced hyperglycemia and five (5) normoglycemic rats served as the negative control group.

\subsection{Experimental Design}

After the induction of experimental diabetes in the Wistar rats, the animals were randomly divided into four treatment and one control groups of five rats each. All the animals were fasted for 16-18 hours before the commencement of treatment and the treatment lasted for 4 weeks as follows: Weeks 1, 2, 3 and 4, all treatments were administered via oral route.

Group $1(\mathrm{n}=5)$ : Diabetic group that received $0.1 \mathrm{mg} / \mathrm{kg}$ of selenium yeast only [24].

Group $2(\mathrm{n}=5)$ : Diabetic group that receive $0.2 \mathrm{mg} / \mathrm{kg}$ of selenium yeast.

Group $3(\mathrm{n}=5)$ : Diabetic group that received $1 \mathrm{mg} / \mathrm{kg}$ of Glibenclamide (GBA).

Group $4(n=5)$ : Normoglycemic group that received $0.9 \%$ normal saline $5 \mathrm{ml} / \mathrm{kg}$.

Group $5(\mathrm{n}=5)$ : Diabetic control group that receive only $0.9 \%$ normal saline $5 \mathrm{ml} / \mathrm{kg}$.

Group $6(\mathrm{n}=5)$ : Diabetic group that receive $300 \mathrm{mg} / \mathrm{kg}$ moderate dose of Aspirin [13].

Group $7(\mathrm{n}=5)$ : Diabetic group that receive $120 \mathrm{mg} / \mathrm{kg}$ of Ibuprofen.

\subsection{Blood Glucose Level Determination}

Blood samples were collected from the rat's tail weekly for the period of 4 weeks. Determination of blood glucose level was done by the glucose-oxidase principle [14], using the digital glucometer (Accu-Check Advantage, Roche Diagnostic, Germany), and results were recorded as $\mathrm{mg} / \mathrm{dl}$ [15].

\subsection{Statistics}

The data obtained were expressed as mean \pm standard error of mean (SEM) and data were statistically analyzed using analysis of variance (ANOVA) followed by Tukey'spost hoc test. The values of $p \leq 0.05$ was considered as significant.

\section{Results}

Statistical analysis of variance (ANOVA) showed that in the comparison with the control group (i.e. Group IV), plasma glucose levels in all the groups treated with STZ were significantly higher when compared with Group IV at WK0. Plasma glucose level in diabetic control (i.e. Group V) was significantly higher when compared with Group IV through all the 4weeks of treatments. In between groups comparison, Group I did not show any significant change in plasma glucose levels when compared with Group V, however plasma glucose levels were significantly lower in Group II after WK1 and WK3 when compared with Group V. Similarly, Group III showed significant lower plasma glucose levels when compared with Group V. Groups VI and VII showed significant lower plasma glucose levels when compared with Group V only after WK3. There was no significant difference when Group II was compared with Group III or VI or VII. 
Table 1. Shows the results of the changes in plasma glucose levels $(\mathrm{mg} / \mathrm{dl})$ during the treatments for 4 weeks.

\begin{tabular}{|c|c|c|c|c|c|}
\hline & Wk0 (mg/dl) & Wk1 (mg/dl) & Wk2 (mg/dl) & Wk3 (mg/dl) & Wk4 (mg/dl) \\
\hline $\begin{array}{l}\text { Group I } \\
(0.1 \mathrm{mg} / \mathrm{kg} \text { Selenium })\end{array}$ & $\bullet 306.40 \pm 52.87 \mathrm{~ns}$ & $285.80 \pm 67.80 \mathrm{~ns}$ & $290.40 \pm 82.63 \mathrm{~ns}$ & $221.00 \pm 68.69 \mathrm{~ns}$ & $199.40 \pm 51.29 \mathrm{~ns}$ \\
\hline $\begin{array}{l}\text { Group II } \\
(0.2 \mathrm{mg} / \mathrm{kg} \text { Selenium })\end{array}$ & $299.20 \pm 41.33 \mathrm{~ns}$ & $\bullet 162.80 \pm 36.31$ & $207.40 \pm 52.35 \mathrm{~ns}$ & $\bullet 107.40 \pm 10.53$ & $175.20 \pm 44.32 \mathrm{~ns}$ \\
\hline $\begin{array}{l}\text { Group III } \\
(1 \mathrm{mg} / \mathrm{kg} \mathrm{GBA})\end{array}$ & $\downarrow 310.60 \pm 51.31 \mathrm{~ns}$ & $\$ 159.00 \pm 31.27$ & $298.60 \pm 62.54 \mathrm{~ns}$ & $\$ 90.80 \pm 5.94$ & $211.40 \pm 40.20 \mathrm{~ns}$ \\
\hline $\begin{array}{l}\text { Group IV } \\
\text { (normal control) }\end{array}$ & $66.20 \pm 1.66$ & $106.60 \pm 4.02$ & $79.60 \pm 4.13$ & $72.00 \pm 1.87$ & $69.40 \pm 1.03$ \\
\hline $\begin{array}{l}\text { Group V } \\
\text { (diabetic control) }\end{array}$ & $\dagger 361.80 \pm 60.34$ & $\dagger 356.00 \pm 59.07$ & $\dagger 327.40 \pm 35.20$ & $\dagger 347.20 \pm 49.76$ & $\dagger 358.60 \pm 59.62$ \\
\hline $\begin{array}{l}\text { Group VI } \\
\text { (300mg/kg Aspirin) }\end{array}$ & $\diamond 320.20 \pm 30.19 \mathrm{~ns}$ & $247.20 \pm 29.02 \mathrm{~ns}$ & $197.00 \pm 10.07 \mathrm{~ns}$ & $\alpha 129.40 \pm 38.64$ & $224.00 \pm 43.81 \mathrm{~ns}$ \\
\hline $\begin{array}{l}\text { Group VII } \\
\text { (120mg/kg Ibuprofen) }\end{array}$ & $\$ 320.40 \pm 18.12 \mathrm{~ns}$ & $265.00 \pm 26.79 \mathrm{~ns}$ & $220.20 \pm 58.04 \mathrm{~ns}$ & $\beta 130.20 \pm 7.59$ & $200.80 \pm 31.26 \mathrm{~ns}$ \\
\hline
\end{tabular}

$\dagger P<0.05$ Group V vs. IV; $\bullet P<0.05$ Group II vs. V; $\ddagger P<0.05$ Group III vs. V; $\alpha P<0.05$ Group VI vs. V; $\beta P<0.05$ Group VII vs. V; $\infty P<0.05$ Group I vs. V; $P<0.05$ IV vs. Groups treated with STZ (i.e. I\&II\&III\&VI\&VII) at WK0; ns= non-significant

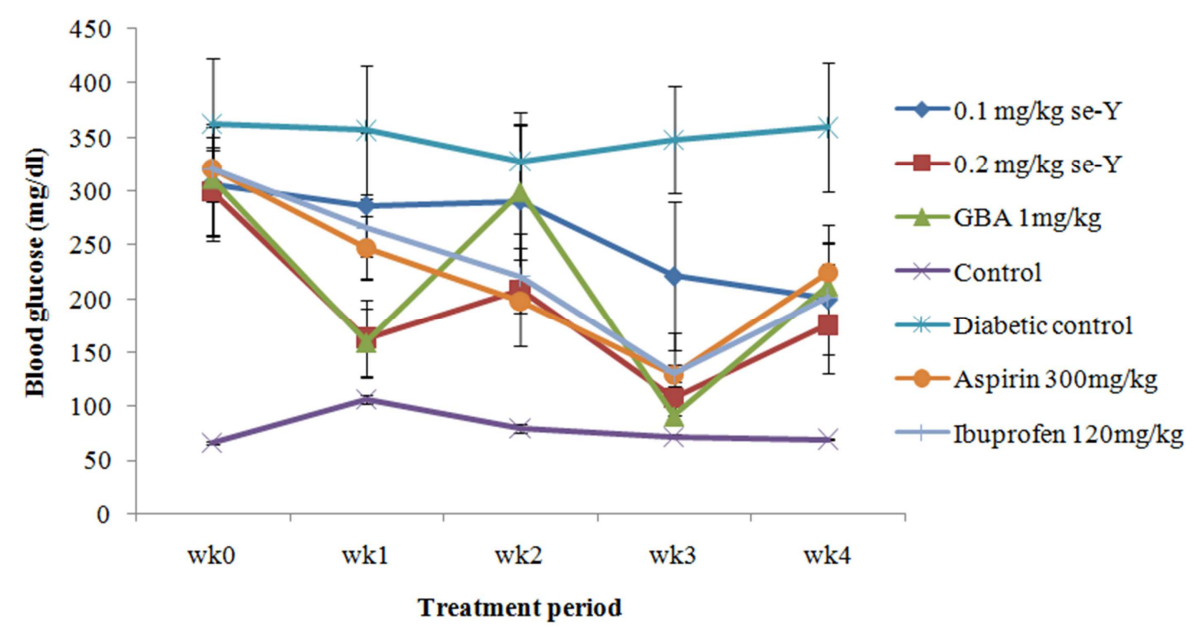

Figure 1. Effect of Selenium-Yeast on blood glucose level in STZ induced diabetes.

\section{Discussion}

The results of the present study showed that blood plasma glucose level in the diabetic control group was significantly higher when compared with the normal control group in the entire 4-weeks of the study. The effect of selenium yeast on blood plasma glucose level was determined by comparing the values in the diabetic control group (i.e. Group V) with the values in Group I (i.e. $0.1 \mathrm{mg} / \mathrm{kg}$ selenium-yeast group) and in Group II (i.e. $0.2 \mathrm{mg} / \mathrm{kg}$ selenium-yeast group). The results showed that, there was no significant difference in blood plasma glucose levels in Group I when compared with Group $\mathrm{V}$ however, blood plasma glucose levels were significantly lower in the $0.2 \mathrm{mg} / \mathrm{kg}$ selenium group (i.e. Group II) at WK1 and WK3 when compared with the diabetic control Group.

Similarly, the lowering effect of glibenclamide on blood plasma glucose level in the study, determined by comparing the values in the diabetic control group with the group that received $1 \mathrm{mg} / \mathrm{kg} /$ day $/ 4$ weeks of glibenclamide (i.e. Group V vs. Group III) showed that glibenclamide significantly lowered blood plasma glucose levels at WK1 and WK3 of the treatments. In addition, the comparison of the blood plasma glucose levels of Group VI that (received $300 \mathrm{mg} / \mathrm{kg} /$ day $/ 4$ weeks of aspirin) and VII that (received $120 \mathrm{mg} / \mathrm{kg} /$ day $/ 4$ weeks of Ibuprofen)with that of diabetic control showed that the anti-inflammatory drugs, aspirin and ibuprofen also possess significant blood plasma glucose lowering effect only at WK3. Furthermore, between groups' comparison showed that there were no significant differences in the hypoglycaemic effect of aspirin, ibuprofen, glibenclamide and selenium-yeast. These results put together suggest that $0.2 \mathrm{mg} / \mathrm{kg}$ and not $0.1 \mathrm{mg} / \mathrm{kg}$ of selenium-yeast possesses hypoglycaemic property that is comparable to the hypoglycaemic property of the oral-hypoglycaemic drug, glibenclamide and the anti-inflammatory drugs, aspirin and ibuprofen but with earlier onset time than the antiinflammatory drugs. Generally, the hypoglycaemic effect of selenium-yeast observed in the study appears to be in disagreement with the results of related studies that suggested that Se could cause glucose disturbance and increase the risk for DM $[16,17,23]$.

Glibenclamide is a well-known oral hypoglycaemic drug 
that belongs to the family of the sulfonylureas a first generation anti-diabetic drug; it elicits its hypoglycaemic effect mainly by acting on ATP-sensitive potassium channel in pancreatic beta-cells.

The pain killer effect of the anti-inflammatory drugs are best known for their effects on the two cyclooxygenase enzymes (COX1 and COX2), but in addition, antiinflammatory drugs could specifically inhibit the protein Ikappa- $\beta$-kinase beta (IKK-beta). This kinase is used for its role in the cascade of signals that activate the nuclear factor kappa-b (NF-kappa-B) family of cellular genes which regulate inflammatory and immune responses. Now, it turns out that IKK-beta also works in another pathway to contribute to insulin resistance by interfering with insulin signalling. Therefore, inhibition of this protein by antiinflammatory drugs may contribute to the hypoglycaemic property of this class of pain killer [13].

The effect of selenium-yeast on blood plasma glucose levels have been reported in several studies on both human and experimental animal, however the overall results are controversial. Conflicting results were reported on the prevalence of diabetes in correlation with serum selenium levels $[18,19]$, Similarly, studies on the protective effect of long-term selenium supplementation reported that selenium does not seem to prevent diabetes or improve blood plasma glucose levels and that it may increase risk for the disease $[16,17]$. However, evidence from other studies suggests that selenium could enhance insulin sensitivity and improve blood plasma glucose levels by mediating insulin-like actions $[20,21]$ and by acting via several other mechanisms, including detoxifying liver enzymes, exerting antiinflammatory effect, and providing antioxidant defense to elicits its anti-diabetic effect, however, the mechanisms by which Se exerts these beneficial effects are still not yet fully understood [7,8,23]. Therefore, more studies should be conducted on selenium-yeast to determine the probable mechanisms via which Selenium is eliciting the hypoglycemic effect observed in the study.

\section{References}

[1] World Health Organization (2010). Diabetes mellitus report of a WHO study Group,

[2] World Health Organization (WHO) (2008). Obesity. Available at: www.who/obesity.org

[3] Ime, F.A., Atangwho, I.J., Regina, I., Ejemot-Nwadiaro, I., Edisua, H.I. and Essien, U. (2011). Hypoglycaemic effect and proximate composition of some selected Nigerian traditional diets used in management of diabetes mellitus; European Journal of Food Research and Review, 1(2): 94- 101.

[4] Otieno, F.F. (2006). Clinical care of type 2 diabetes in subSaharan Africa. International Diabetes Monitoring, 18: 5-11.

[5] Peltzer, K., Khoza, L.B. and Lekhuleni, M.E. (2001). Concepts and treatment for diabetes among traditional and faith healers in the northern province, South Africa. Curationis Journal, 24: 42-7.
[6] Levitt, N.S. (2008). Diabetes in Africa: epidemiology, management and healthcare challenges. 695 Heart, 94 (11): 1376-1382.

[7] Thomson, C.D. (2004). Assessment of requirements for selenium and adequacy of selenium status: a review. European Journal of Clinical Nutrition., 58:391-402.

[8] Tinggi, U. (2008). Selenium: its role as antioxidant in human health. Environmental Health and Preventive Medicine, 13:102-108.

[9] Yiming, X., Kristina, E., Daniel, W., Jiayuan, X. and Raymond, F. (2005). Effectiveness of selenium supplements in a low-selenium area of China. American Journal of Clinical Nutrition, 81(4): 829-834.

[10] Schrauzer, G. (2000). Selenomethionine: A review of its nutritional significance, metabolism and toxicity. Journal of Nutrition, 130:1653-1656.

[11] Lovell, M, Xiong, S., Lyubartseva, G.andMarkesbery, W. (2009) (Sel-Plex diet) decreases amyloid burden and RNA and DNA oxidative damage in APP/PS1 mice. Free Radical Biology and Medicine, 46:1527-1533.

[12] Al-Othman, Z.A., Aboul-Soud, M., Al-Othman, A.M., ElDesoky, G.E., Yusuf K, A. J. and Al-Khedhairy, A.A (2011). Hepatoprotective Effects of Vitamin E/Selenium against Malathion-Induced Injuries on the antioxidant Status and Apoptosis-Related Gene Expression in Rats. Journal ofToxicological Science, 36: 285-296.

[13] Hammadi, S.H., Saeed, S.A., Ahmad, I.Y., Saad, D.A. (2012). Aspirin and Blood Glucose and Insulin Resistance. Open Journal of Endocrine and Metabolic Diseases, 2, 16-26.

[14] Beach, E.F., Turner, J.J. (1958). An enzymatic method for glucose determination in body fluid.Clinical chemistry, 4:462468

[15] Rheney, C.C., Kirk, K.K. (2000). Performance of three blood glucose meters. Annal of Pharmacother. March, 34(3): 317-21.

[16] Laclaustra, M., Navas-Acien, A., Stranges, S., Ordovas, J.M. and Guallar, E. (2009). Serum selenium concentrations and diabetes in U.S. adults: National Health and Nutrition Examination Survey (NHANES) 2003-2004. Environmental Health Perspective, 117:1409-1413.

[17] Bleys, J., Navas-Acien, A. and Guallar E. (2007). Serum selenium and diabetes in U.S. adults. Diabetes. Care, 30:829834 .

[18] Czernichow, S., Couthouis, A., Bertrais, S., Vergnaud, A.C., Dauchet, L., Galan, P. and Hercberg S. (2006). Antioxidant supplementation does not affect fasting plasma glucose in the Supplementation with Antioxidant Vitamins and Minerals (SU.VI.MAX) study in France: association with dietary intake and plasma concentrations. American Journal of Clinical Nutrition, 84:395-399.

[19] Stranges, S., Marshall, JR., Natarajan, R., Donahue, R.P., Trevisan, M., Combs, G.F., Cappuccio, F.P., Ceriello, A. and Reid, M.E. (2007). Effects of long-term selenium supplementation on the incidence of type 2 diabetes: a randomized trial. Annals of Intern ational Medicine, 147:217223.

[20] Stapleton, S.R. (2000). Selenium: an insulin-mimetic. Cellular and Molecullar Life Sciences, 57:1874-1879. 
[21] Mueller, A.S. and Pallauf, J. (2006). Compendium of the antidiabetic effects of supra-nutritional selenate doses. In vivo and in vitro investigations with type II diabetic $\mathrm{db} / \mathrm{db}$ mice. Journal of Nutrition and Biochemistry, 17: 548-560.

[22] Lawal, H.A., Atiku,M.K., Khelpai, D.G. and Wannag, N.N. (2008). Hypoglycaemic and hypolipidaemic effects of the aqueous leaf extract of Murrayakoenigiiin normal andalloxan - diabetic rats. Nigerian Journal of PhysiologicalSciences 23 (1-2): $37-40$

[23] Rocourt, C.R. and Cheng, W.H. (2013). Selenium supranutrition: Are the potential benefits of chemoprevention outweighed by the promotion of diabetes and insulin resistance? Nutrients; 5(4):1349-65.
[24] Nouf, M. A., Hala, A. A., Raeesa, A. M., Nawal, M. A. and Maha, A. (2013). Preventive Effects of Selenium Yeast, Chromium Picolinate, Zinc Sulfate and their Combination on Oxidative Stress, Inflammation, Impaired Angiogenesis and Atherogenesis in Myocardial Infarction in Rats.Journal of Pharmacy and Pharmaceutical Sciences, 16(5) 848-867

[25] Burcelin R., Eddouks M., Maury J., Kande J., AssanR.and Girard J. (1995). Excessive glucose production, rather than insulin resistance, accounts for hyperglycemia in recent-onset streptozotocin-diabetic diabetic rats. Diabetologia, 38, 283290. 